\title{
PENGARUH PEMIJATAN PADA BAYI TERHADAP KENAIKAN BERAT BADAN BAYI
}

The Effect of Baby Massage On The Increase In Baby's Body Weight

\author{
Suntin*, Nur Halimah, Fauziah Botutihe \\ Akademi Keperawatan Pelamonia Kesdam VII/Wirabuana \\ *suntin1983@gmail.com, 081355290933
}

\begin{abstract}
Massage that is done properly and regularly on babies is thought to have various organs of the body. Massage that is done properly and regulary on babies is thought to have various benefits in the process of baby development. Massage on babies by parents can improve the emotional relationship between parents and babies, and to increase the baby's weight. The purpose of this study was to determine the effect of infant massage on infant weight gain. This thype of research is analytic observasional research with pre-experimental research design with pretest-posttest design, namely giving a pretest (initial observation) to the control and intervention groups first before being given intervention, after that given intervention (baby massage therapy), then posttest (final observation) in the control and intervention groups. The results showed that in the intervention group, 17 infants had a median weight of 5300 grams before the massage and after the massage was carried out at week 2, measurements were made and the results showed a median 5900 grams. Meanwhile, the median value of changes that occured was $0.20 \mathrm{grams}$. As a statistical test using the wilcoxon test, the value of $0.000(p<0.05)$ was obtained, this indicates that there was a significant change in the increase in body weight of infants who were given baby massage intervention, in the control group of 17 infants who were not treated amounting to 4000 grams and after the second week of measurement again showed a median value of 3900 grams. While the median value of changes that occured was -0.10 grams. As with the statistical test using the Wilcoxon test for this group, the value was 0.270 ( $p>0.05$ ), this indicates that there was no significant change. The conclusion of this study is that there is an effect of infant massage on the increase in baby weight.
\end{abstract}

Keywords : Baby massage, increase body weight, infant aged $0-6$ months

\section{ABSTRAK}

Pijat yang dilakukan secara benar dan teratur pada bayi diduga memiliki berbagai keuntungan dalam proses tumbuh kembang bayi. Pijat pada bayi oleh orangtua dapat meningkatkan hubungan emosional antara orangtua dan bayi, juga diduga dapat meningkatkan berat badan bayi. Adapun tujuan dari penelitian ini adalah untuk mengetahui pengaruh pemijatan bayi terhadap kenaikan berat badan bayi. Jenis penelitian yang digunakan adalah penelitian observasional analitik dengan desain penelitian pra-experimental dengan pretest-posttest design yaitu memberikan pretest (pengamatan awal) pada kelompok kontrol dan intervensi terlebih dahulu sebelum diberikan intervensi, setelah itu diberikan intervensi (terapi pijat bayi), kemudian dilakukan posttest (pengamatan akhir) pada kelompok kontrol dan intervensi. Hasil menunjukkan pada kelompok intervensi dimana 17 bayi berat badan bayi sebelum dilakukan pemijatan nilai median sebesar 5300 gram dan setelah dilakukan pemijatan pada minggu ke 2 dilakukan pengukuran dan hasilnya menunjukkan nilai median sebesar $5900 \mathrm{gram}$. Sedangkan nilai median perubahan yang terjadi sebesar 0,20 gram. Sebagaimana uji statistik dengan menggunakan Uji Wilcoxon diperoleh nilai sebesar $0,000(p<0,05)$, hal ini menunjukkan bahwa terdapat perubahan yang bermakna terhadap peningkatan berat badan bayi yang diberikan intervensi pemijatan bayi, pada kelompok kontrol dari 17 bayi yang tidak dilakukan intervensi nilai median sebesar 4000 gram dan setelah minggu ke 2 dilakukan pengukuran kembali menunjukkan nilai median sebesar 3900 gram. Sedangkan nilaimedian perubahan yang terjadi sebesar $-0,10$ gram. Sebagaimana uji statistik dengan menggunakan Uji Wilcoxon untuk kelompok ini diperoleh nilai sebesar $0,270(p>0,05)$ hal ini menunjukkan bahwa tidak terdapat perubahan yang bermakna. Kesimpulan dari penelitian ini adalah ada pengaruh pemijatan bayi terhadap peningkatan berat badan bayi.

Kata kunci : Bayi umur $0-6$ bulan, Kenaikan berat badan, Pijat bayi,

\section{PENDAHULUAN}

Pada masa perkembangan bayi merupakan masa keemasan karena masanya sangat singkat dan tidak dapat diulang. Pada pertumbuhan dan perkembangan yang optimal merupakan hasil interaksi yang saling berkaitan, pertumbuhan dan perkembangan berbeda dari segi perubahan fisik dari masing-masing individu juga dari segi kemampuan dan keterampilan yang dimiliki setiap individu. Pada pijat bayi memberikan banyak manfaat yakni peningkatan produksi ASI dan kenaikan berat badan 
bayi (Sugiharti, 2016). Dalam masa keemasan dapat juga dikatakan masa kritis karena bayi sangat peka terhadap lingkungannya, di Kabupaten Bondowoso contohnya terdapat kenaikan jumlah bayi dengan angka yang berbeda dalam kenaikan berat badan bayi dipengaruhi oleh genetik, lingkungan, tingkat kesehatan, status gizi dan juga latihan fisik(Ulfa \& Munir, 2020).

Saat umur 1-3 bulan bayi juga membutuhkan dekapan, sentuhan dan buain orang tuanya terutama sang ibu (Dewi, 2013). Dewasa ini, para ahli telah dapat membuktikan secara ilmiah tentang apa yang telah lama dikenal manusia, yaitu terapi sentuh dan pijat pada bayi mempunyai banyak manfaat terhadap perubahan fisiologis bayi apalagi dilakukan sendiri oleh ibu bayi. Ibu adalah orang tua paling dekat dengan bayi, dimana pijatan ibu kepada bayinya adalah sapuan lembut pengikat jalinan kasih sayang. Kulit ibu adalah kulit yang paling awal dikenali oleh (Aminati, 2013) Sentuhan dan pijatan yang diberikan ibu adalah bentuk komunikasi yang dapat membangun kedekatan ibu dengan bayi denganmenggabungkan kontak mata, senyuman, ekspresi wajah. Jika stimulasi seringdiberikan, maka hubungan kasih sayang ibu dan bayi secara timbal balik akan semakin kuat (Dewi, 2010).

Kenaikan berat badan pada bayi dan anak di bawah usia lima tahun (balita) merupakan masalah yang masih dihadapai di Provinsi Sulawesi Selatan. Sepanjang tahun 2008 terdapat 26.274 bayi dan balita yang ditimbang di POSYANDU mengalami masalah dalam penambahan berat badanyaitu berat badan bayi tidak sesuai dengan usia bayi. Pada tahun 2009 kasus yang sama dilaporkan sebanyak 81.837 dan tahun 2010, jumlah ini bertambah menjadi 87.000 dari total bayi di Provinsi Sulawesi Selatan sebanyak 497.577 bayi dan balita (Dinkes Provinsi Sul-Sel, 2010). Dinas Kesehatan Kabupaten Maros Sulawesi Selatan melaporkan bahwa pada tahun 2010, hasil penimbangan bayi dan balita tercatat 2.415 bayi/balita yang mengalami gangguan kenaikan berat badan dan berdasarkan data dalam Kartu Menuju Sehat (KMS) sebagian besar berada di garis kuning bahkan di bawah garis merah (Dinkes Maros, 2010). Dari masalah di atas, perlu ada upaya untuk meningkatkan berat badan bayi, salah satunya dengan pijat bayi.

\section{METODE}

\section{Desain, tempat dan waktu}

Jenis penelitian yang digunakan adalah penelitian observasional analitik dengan desain penelitian pra-experimental dengan pretest-posttest design yaitu memberikan pretest (pengamatan awal) pada kelompok kontrol dan intervensi terlebih dahulu sebelum diberikan intervensi, setelah itu diberikan intervensi (terapi pijat bayi), kemudian dilakukan posttest (pengamatan akhir) pada kelompok kontrol dan intervensi. Penelitian dilaksanakan di wilayah kerja Poliklinik Kesehatan 07.09.05 Monginsidi Kelurahan Panambungan Kecamatan Mariso Kota Makassar dan pemijatan dilakukan dirumah responden.

\section{Jumlah dan cara pengambilan}

Populasi dalam penelitian ini adalah seluruh bayi yang berusia 0 - 6 bulan pada bulan Januari sampai Juli 2020. Kelompok eksperimen 17 bayi dan kelompok kontrol 17 bayi. Teknik pengambilan sampel pada penelitian ini adalah dengan cara menggunakan Non Probability Sampling yaitu jenis teknik Purpossive Sampling.

Setiap subjek yang memenuhi kriteria inklusi peneliti langsung meminta inform consent dan melakukan proses pengumpulan data dengan cara pengukuran langsung kepada responden (pre test) yaitu mengukur berat badan bayi pada kelompok eksperimen dan kelompok kontrol dengan menggunakan timbangan bayi OneMed dengan akurasi pengukuran $0,05 \mathrm{~kg}$ untuk $0-10 \mathrm{~kg}$ dengan kapasitas maksimalnya $20 \mathrm{~kg}$. Peneliti dibantu oleh 2 anggota peneliti yaitu dosen Akper Pelamonia.

\section{HASIL}

Hasil pengukuran ini dilakukan pada kelompok eksperimen setelah ibu responden melakukan terapi pijat kepada bayinya selama $2 \times 15$ menit (pagi dan sore) dalam 2 minggu. Sedangkan pada kelompok kontrol setelah 2 minggu penelitian, peneliti mengukur berat badan bayi dan memberikan edukasi dan pengajaran tentang terapi pijat bayi dengan menggunakan lembar balik dan leaflet. Analisis yang digunakan pada penelitian iniadalah dengan uji Wilcoxon.

\section{Karakteristik Umum Responden}

a. Jenis Kelamin

Tabel 1

Karakteristik Responden Berdasarkan Jenis Kelamin

\begin{tabular}{lcc}
\multicolumn{3}{c}{ Bayi } \\
\hline Jenis Kelamin & Jumlah & Persentase \\
\hline Laki-laki & 9 & $26,5 \%$ \\
Perempuan & 25 & $73,5 \%$ \\
\hline Jumlah & 34 & $100,0 \%$
\end{tabular}

Sumber : Hasil Olahan Data Primer, 2020

Berdasarkan tabel 1 di atas diketahui bahwa dari 34 responden, terdiri dari laki-laki 9 orang $(26,5 \%)$ dan perempuan 25 orang $(73,5 \%)$ 
b. Umur

Tabel 2

Karakteristik Responden Berdasarkan Umur Bayi

\begin{tabular}{c|c|c}
\hline Usia & Jumlah & Persentase \\
\hline 0 bulan & 10 & $29 \%$ \\
1 bulan & 6 & $18 \%$ \\
2 bulan & 2 & $6 \%$ \\
3 bulan & 5 & $15 \%$ \\
4 bulan & 2 & $6 \%$ \\
5 bulan & 4 & $12 \%$ \\
6 bulan & 5 & $15 \%$ \\
\hline Jumlah & 34 & $100,0 \%$ \\
\hline
\end{tabular}

Sumber : Hasil Olahan Data Primer, 2020

Berdasarkan tabel 2 di atas diketahui bahwa dari 34 responden, bayi berusia 0 bulan 6 orang $(29,4 \%)$, bayi usia 1 bulan 6 orang $(17,6 \%)$, bayi usia 2 bulan 2 orang $(5,9 \%)$, bayi berusia 3 bulan 4 orang $(12 \%)$, bayi yang berusia 4 bulan 2 orang $(6 \%)$, bayi yang berusia 5 bulan 4 orang (12\%), bayi yang berusia 6 bulan 5 orang (15\%).

\section{Analisis Bivariat}

Tabel 3

Distribusi Data Berat Badan Bayi Pre Test - Post

Test Pada Kelompok Perlakuan dan Kelompok

Kontrol

\begin{tabular}{lcccll}
\hline \multirow{2}{*}{$\begin{array}{l}\text { Kelom } \\
\text { pok }\end{array}$} & Juml & \multicolumn{3}{c}{ Median (Min/Maks) } & Nilai $p^{*}$ \\
\cline { 3 - 5 } & & $\begin{array}{c}\text { Pre } \\
\text { Test }\end{array}$ & $\begin{array}{c}\text { Post } \\
\text { Test }\end{array}$ & Perubahan & \\
\hline Interve & 17 & 5.300 & 5.900 & $0.20(0.10-$ & 0.000 \\
nsi & & $(2.800-$ & $(3.400-$ & $0.70)$ & \\
& & $7.800)$ & $7.900)$ & & \\
\hline Kontrol & 17 & 4.000 & 3.900 & -0.10 & 0.270 \\
& & $(2.500-$ & $(2.400-$ & $(-0.30 / 0.60)$ & \\
& & $9.800)$ & $9.500)$ & & \\
\hline
\end{tabular}

Sumber : Hasil Olahan Data Primer, 2020

Berdasarkan tabel 3 menunjukkan pada kelompok intervensi dimana 17 bayi berat badan bayi sebelum dilakukan pemijatan nilai median sebesar 5300 gram dan setelah dilakukan pemijatan pada minggu ke 2 dilakukan pengukuran dan hasilnya menunjukkan nilai median sebesar 5900 gram.Sedangkan nilai median perubahan yang terjadi sebesar 0,20 gram. Sebagaimana uji statistik dengan menggunakan Uji Wilcoxon diperoleh nilai sebesar $0,000(p<0,05)$ hal ini menunjukkan bahwa terdapat perubahan yang bermakna terhadap peningkatan berat badan bayi yang diberikan intervensi pemijatan bayi, pada kelompok kontrol dari 17 bayi yang tidak dilakukan intervensi nilai median sebesar 4000 gram dan setelah minggu ke 2 dilakukan pengukuran kembali menunjukkan nilai median sebesar 3900 gram. Sedangkan nilaimedian perubahan yang terjadi sebesar -0,10 gram. Sebagaimana uji statistik dengan menggunakan Uji Wilcoxon untuk kelompok ini diperoleh nilai sebesar $0,270 \quad(p>0,05)$ hal ini menunjukkan bahwa tidak terdapat perubahan yang bermakna.

\section{PEMBAHASAN}

Karakteristik responden

a. Umur

Dari tabel 1 di atas dari 32 responden menunjukkan yang paling banyak bayi berumur 0 bulan (neonatus) yaitu sebanyak 10 bayi $(29 \%)$ dan yang paling sedikit bayi berumur 2 bulan $(6 \%)$ dan 4 bulan (6\%). Menurut Soetjiningsih kebutuhan dasar anak terbagi atas kebutuhan fisik biomedis (asuh), kebutuhan emosi/kasih sayang (asih) dan kebutuhan akan stimulasi mental (asah). Kebutuhan fisik meliputi pangan/gizi yang merupakan kebutuhan terpenting. Kebutuhan dasar anak kedua adalah kebutuhan emosi/kasih sayang. Pada tahun-tahun pertama kehidupan hubungan yang erat, mesra dan selaras antara ibu dengan anak merupakan syarat mutlak untuk menjamin tumbuh kembang anak baik fisik, mental maupun psikososial. Peningkatan berat badan bayi ini disebabkan oleh terjadi karena bayi yang dipijat mengalami peningkatan tonus nervus vagus (saraf otak ke-10) yang membuat kadar enzim penyerapan gastrin dan insulin meningkat sehingga penyerapan sari makanan menjadi lebih baik.

b. Jenis Kelamin

Berdasarkan tabel 1 di atas diketahui bahwa dari 34 responden, terdiri dari laki-laki 9 orang $(26,5 \%)$ dan perempuan 25 orang $(73,5 \%)$ Peningkatan berat badan bayi sebelum dan sesudah pada kelompok intervensi dan kelompok kontrol.

Analisis bivariat

Uji statistic Wilcoxon Sign Rank Test menunjukkan nilai $p$ sign $Z$ tabel sehingga terdapat pengaruh pijat bayi terhadap kenaikan berat badan bayi usia 1-7 bulan. Berat badan merupakan hasil peningkatan atau penutupan semua jaringan yang ada pada tubuh lain : tulang, otot, caiaran tubuh dan yang lainnya (Soetjiningsih, 2005 :38). Pertumbuhan dan perkembangan merupakan proses yang terjadi pada makhluk hidup. Pertumbuhan dan perkembangan menyangkut semua aspek semua kemajuan yang dicapai sejak dalam kandungan hingga dewasa. Hal ini sejalan dengan penelitian Ida Sulsila (2017) yang menunjukkan bahwa terdapat pengaruh yang signifikan pijat bayi terhadap kenaikan berat badan bayi dengan signifikasi sebesar 0,000. Dengan hasil t tabel sebesar 0,0 dan $p$ sebesar 0,000 . Hal ini menunjukkan nilai $p<0,05$ dan nilai $z$ sebesar 3,793 maka H1 diterima.

Hal ini sejalan dengan penelitian Nina Tresnayanti (2019) dimana Hasil analisis univariat didapatkan data bahwa nilai rata-rata keterampilan pijat bayi pada kelompok intervensi meningkat $90 \%$ hasil post test nya . Hasil perhitungan nilai probabilitas diperoleh bahwa hanya 5 dari 1000 orang yang 
keterampilannya akan meningkat apabila tidak diberikan pelatihan tentang teknik pijat bayi. Kesimpulan Hasil uji statistik ini menunjukan bahwa secara statistik pelatihan teknik pijat bayi secara signifikan bisa meningkatkan keterampilan dalam memijat bayi.

Dari hasil penelitian yang telah dilakukan di desa Baruharjo didapatkan bahwa rerata peningkatan berat badan pada kelompok perlakuan 440 dan pada kelompok kontrol 340. Dengan uji paired t-test didapatkan bahwa kelompok perlakuan korelasinya sangat kuat dari pada kelompok kontrol, keadaan ini menunjukkan bahwa masukan nutrisi pada kelompok perlakuan lebih baik dari pada kelompok kontrol. Hasil tersebut diperkuat dengan hasil dari hasil uji Independent t-test yang didapatkan bahwa ada perbedaan rata-rata berat badan antara yang diberi pemijatan dengan bayi yang tidak mendapat pemijatan.

Fakta ini diperkuat pendapat Roesli (2001) yang menyatakan pijat bayi mempunyai banyak manfaat diantaranya meningkatkan hubungan emosi antara orangtua dan bayi sehingga dapat menstimulus perkembangan personal sosial bayi, selain itu gerakan remasan pada pijat bayi berfungsi untuk menguatkan otot bayi sehingga dapat menstimulus perkembangan motoriknya.

Pijat bayi merupakan pengungkapan rasa kasih sayang antara orang tua dengan anak lewat sentuhan pada kulit. Sentuhan dan pelukan seorang ibu merupakan kebutuhan dasar bayi. Sentuhan yang dihadirkan dalam pijatan-pijatan lembut untuk bayi merupakan sebuah stimulus yang penting dalm tumbuh kembang anak. Pijat adalah terapi sentuh tertua yang dikenal manusia (Warsini and Nugraini, 2016) (Kusmini, 2014). Salah satu mekanisme dasar pijat bayi adalah aktivitas Nervus Vagus meningkatkan volume ASI yaitu penyerapan makanan menjadi lebih baik karena peningkatan Aktivitas Nervus Vagus menyebabkan bayi cepat lapar sehingga akan lebih sering menyusu pada ibunya. Seperti diketahui, ASI akan semakin banyak diproduksi jika semakin banyak diminta. selain itu, ibu yang memijat bayinya akan merasa lebih tenang dan hal ini berdampak positif pada peningkatan volume ASI (Rahayu, Santoso and Yunitasari, 2015). Sentuhan akan merangsang peredaran darah dan menambah energi. Sebenannya, pijat berguna tidak hanya untuk bayi sehat tetapi juga bayi sakit. Bahkan, bagi anak sampai orang dewasa sekalipun. Para ahli kesehatan menemukan pijatan dengan teknik yang tepat dalam kondisi sehat. Menurut Kusmini (2014), bahwa ada istilah pemijatan tradisional dan pemijtan modern pada bayi (Kusmini, 2014).

Dari uraian diatas menunjukkan bahwa pemijatan berpengaruh terhadap paningkatan berat badan. Hal ini dikarenakan dengan pemijatan dapat merangsang peningkatan masukan makanan yang dapat meningkatkan berat badan bayi. Tetapi bila dilihat pada berat badan awal, pada kelompok perlakuan reratanya lebih baik dari pada kelompok kontrol. Dan berat badan setelah dua minggu menunjukkan bahwa berat badan bayi meningkat dengan rerata kelompok perlakuan tetap baik dari pada kelompok kontrol menunjukkan hasilnya bias dan tidak maksimal karena rerata berat badan awal bayi sudah berbeda. Dari hasil tersebut sesuai dengan teori yang dinyatakan Ganong (1997) bahwa pertumbuhan setiap individu bervariasi dan bersifat linier dengan proses episodik, yang mana penyebab pertumbuhan episodik tidak dapat diketahui.

\section{KESIMPULAN}

Kesimpulan dari penelitian ini adalah ada pengaruh pemijatan bayi terhadap peningkatan berat badan bayi.

\section{UCAPAN TERIMA KASIH}

Penulis menyampaikan terima kasih kepada Direktorat Riset dan Pengabdian Masyarakat Direktorat Jenderal Riset dan Pengembangan Kementerian Riset, Teknologi, dan Pendidikan Tinggi yang telah mendanai sepenuhnya penelitian ini melalui hibah penelitian dosen pemula. Ketua UP2M serta semua instansi maupun perseorangan yang telah memberikan dukungan moril dan materil selama pelaksanaan penelitian.

\section{DAFTAR PUSTAKA}

Aminati, D. (2013). Pijat dan senam untuk bayi dan balita. Yogyakarta: Brilliant Books.D. Y. Gultom, "Efektifitas Pijat Bayi Terhadap Peningkatan Berat Bayi Prematur di Ruang Perinatologi Rumah Sakit Imelda Medan," vol. 1, no. 1, pp. 27-33, 2015.

Dewi, S. (2013). Pijat dan asupan gizi tepat untuk melejitkan tumbuh kembang anak. Jogjakarta : Pustaka Baru Press.

Dinas Kesehatan Maros. (2010). Maros dalam angka. Maros: Dinas Kesehatan KabupatenMaros.

Dinas Kesehatan Provinsi Sulawesi Selatan (2010). Derajat kesehatan di Sulawesi Selatan Tahun 2010. Makassar: DINKES PEMPROV SulawesiSelatan. 
I. Susila, "Pengaruh Teknik Pijat Bayi Terhadap Kenaikan Berat Badan Bayi Usia 0-7 Bulan," vol. 9, no. 2, pp. 1419,2017

Kalsum. U. (2014). "Peningkatan Berat Badan Bayi Melalui Pemijatan”. Jurnal Keperawatan Indonesia, Volume 17 No.1, hal $25-29$.

Kusmini (2014) Mom Massage. Edited by maulina fildzah Khairani. Semarang: IHCA.

Rahayu, D., Santoso, B. and Yunitasari, E. (2015). "Produksi Asi lbu dengan Intervensi Acupresure Point Lactation dan Pijet Oksitosin (The Difference in Breastmilk Production between Acupresure Point for Lactation and Oxytocin Massage)', jurnal ners. Fakultas Keperawatan Universitas Airlangga, 10(1).

Roesli, U., (2001). "Pedoman Pijat Bayi”. Trubus Agriwidya, Jakarta.

Sugiharti, R. K. (2016). Pengaruh Frekuensi Pijat Bayi Terhadap Pertumbuhan (Berat Badan) Bayi Usia 1-3 Bulan Di Desa Karangsari Dan Purbadan. Jurnal Ilmiah Kebidanan, 7, 41-52. http://www.ojs.akbidylpp.ac.id/index.php/Prada/article/view/140

Soetjiningsih. (2005). Konsep Pertumbuhan Berat Badan: Jakarta.

Tresnayanti. N. (2019). "Efektivitas Pelatihan Pijat Bayi Terhadap Keterampilan Pijat Bayi Pada Ibu Yang Mempunyai Bayi", vol. III No.1

Ulfa, R. B., \& Munir, Z. (2020). Efektifitas Stimulasi Pijat Bayi terhadap Peningkatan Berat Badan Bayi Usia 0-4 Bulan dengan Riwayat BBLR Program Studi Keperawatan Fakultas Kesehatan Universitas Nurul Jadid * Email Korespondensi : renybadariyah@gmail.com Abstrak Stimulation Effectivenes. 3(2), 155-162.

Warsini, W. and Nugraini, D. (2016) _Pengaruh Pijat Bayi Terhadap Lama Tidur Bayi Di Desa Duwet Kecamatan Wonosari Kabupaten Klaten', Jurnal IImu Kesehatan Kosala, 4(1). WHO (2017). France. 